\title{
THE FUZZY ROBUST ANTI-SWAY CRANE CONTROL SYSTEM
}

\section{ZASTOSOWANIE LOGIKI ROZMYTEJ W STEROWANIU ODPORNYM SUWNICĄ POMOSTOWĄ}

\author{
Jarosław Smoczek ${ }^{1}$, Janusz Szpytko ${ }^{2}$ \\ $(1,2)$ AGH University of Science and Technology \\ Faculty of Mechanical Engineering and Robotics \\ al. Mickiewicza 30, 30-059 Kraków \\ E-mail: (1)smoczek@agh.edu.pl, (2)szpytko@agh.edu.pl
}

\begin{abstract}
The paper presents the pole placement approach to solve problem of conventional, based of proportional-derivative controllers, as well as robust, based of fuzzy controller, anti-sway crane control. The methods of robust gain-scheduling crane control system and selecting minimal set of operating points were shown. The fuzzy robust controller, based of Takagi-Sugeno-Kang inference system, was presented, as well as results of experiments, carried out using laboratory model of an overhead traveling crane, were shown in the paper.
\end{abstract}

Keywords: crane, robust control, fuzzy logic

Streszczenie: W artykule przedstawione zostały metody budowy konwencjonalnych, opartych na regulatorach proporcjonalno-różniczkujących i metodzie lokowania biegunów, oraz odpornych, opartych na logice rozmytej układów sterowania mechanizmami ruchu suwnicy pomostowej. Przedstawiono rozwiązanie odpornego układu regulacji pozycji ładunku przemieszczanego przez suwnicę z zastosowaniem rozmytego systemu wnioskowania Takagi-Sugeno-Kang oraz rezultaty eksperymentów przeprowadzonych $\mathrm{Z}$ zastosowaniem laboratoryjnego modelu suwnicy pomostowej.

Slowa kluczowe: suwnica, sterowanie odporne, logika rozmyta 


\section{Introduction}

The problem of positioning a payload shifted by an overhead traveling crane is very interesting from automation point of view and widely studied in researches works owing to necessity of solving the problem of anti-sway crane control system adaptation to changes of control object parameters, that is the result of variables changes - rope length, on which a payload is suspended, and the mass of a payload. This problem becomes essential in the face of higher and higher requirements that are put on time and accuracy of transportation tasks realized in automated industrial processes by material handling devices as well as reliability and exploitation quality of transportation devices. Those requirements can be met by increasing control quality in material handling systems. In case of transportation tasks realized by cranes, expected automation of materials handling process requires implementation in industrial practice the anti-sway control solutions which take into consideration the control object parameters changes.

The approach to the crane control system is mostly considered as problem of ensuring precision positioning of shifted by crane load with reducing swing phenomenon. The proposed solutions in researches works concern crane control systems realized using conventional methods based on PID controller (Proportional-Integrated-Derivative), LQ (linear-quadratic), advanced methods of poles assignment, control observers and robust controllers (Giua, et al., 1999; Hicar, et al., 2006; Lew, and Halder, 2003), as well as intelligent control systems mostly based on fuzzy logic, Mamdani fuzzy inference system (Benhidjeb, and Gissinger, 1995; Manhfouf, et al., 2000; Nalley, and Trabia, 2000; Yi, et al., 2002) and Sugeno models (Smoczek, and Szpytko, 2008), and artificial neural networks or neurofuzzy hybrids (Mendez, et al., 1999; Smoczek, and Szpytko, 2009).

In spite of the problem of anti-sway crane control system is very popular in researches works, the practical methods that lead to work out control algorithm and set control parameters (e.g. parameters of PID controllers) are hardly ever shown. In the paper were presented methods of conventional crane control system parameters deriving based of pole placement method as well as method of gain-scheduling system building with selecting optimal set of operating points. The presented method was used for building robust fuzzy controller with Takagi-Sugeno-Kang (TSK) inference system tested on laboratory model of an overhead traveling crane. 


\section{The anti-sway crane control system with PD controllers}

The simplified model of a crane can be expressed as two-mass model composed of mass of a crane $m_{1}$ and mass of a load $m_{2}$ suspended on a rope with length $l$ (see Figure 1). The parametric model of crane system, which can be achieved from identification process of control object, can be expressed in form of time-discrete transmittances that describe relationships $\alpha(z)=G_{\alpha}(z) \cdot \dot{X}(z)$ and $\dot{X}(z)=G_{\dot{x}}(z) \cdot U(z)$ (see Figure 2).

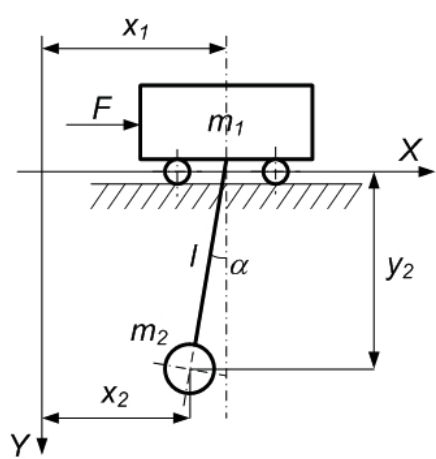

Figure 1. Simplified two-mass model of a crane, where $\alpha$ - the load swing, $F=u-$ driving force/control signal

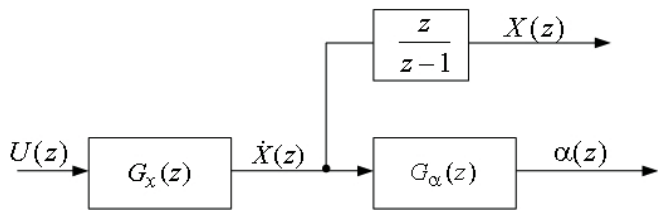

Figure 2. The time-discrete model of a crane, assumed in identification of control object

The assumed for identification of control object models (see Figure 2) were expressed as following:

$$
\begin{aligned}
G_{\alpha}(z) & =\frac{B(z)}{A(z)}=\frac{b_{1} z+b_{0}}{z^{2}+a_{1} z+a_{0}} \\
G_{\dot{x}}(z) & =\frac{D(z)}{C(z)}=\frac{d_{0}}{z+c_{0}}
\end{aligned}
$$

For the assumed form of the control object time-discrete model the antisway crane speed control can be built (see Figure 3) with using crane speed proportional controller $R_{\dot{x}}(z)$ and the load swing time-discrete controller $R_{\alpha}(z)$ expressed as (3) and (4). 


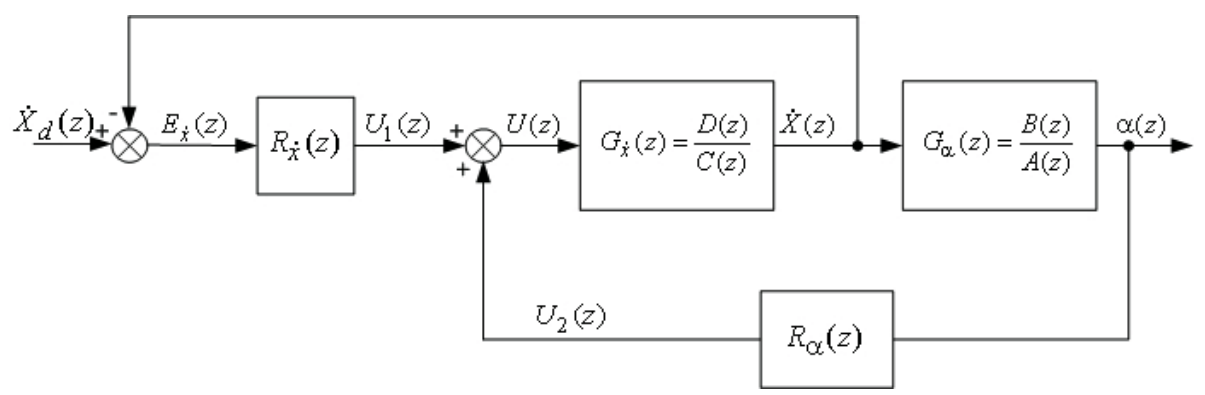

Figure 3. Speed and anti-sway crane discrete control system built for crane parametric model achieved from identification of control object

$$
\begin{aligned}
& R_{\dot{x}}(z)=K_{P \dot{x}} \\
& R_{\alpha}(z)=\frac{Q(z)}{S(z)}=\frac{q_{1} z+q_{0}}{z+s_{0}}
\end{aligned}
$$

The transmittance of closed-loop control system is expressed as equation (5).

$$
G_{C}(z)=\frac{\dot{X}(z)}{\dot{X}_{d}(z)}=\frac{K_{P \dot{x}} \cdot S(z) \cdot B(z) \cdot D(z)}{A(z) \cdot C(s) \cdot S(z)-B(z) \cdot D(z) \cdot Q(z)+K_{P \dot{x}} \cdot A(z) D(z) \cdot S(z)}
$$

The Diophantine equation for characteristic equation of closed-loop control system transfer function (5) can be formulated as (6).

$$
A(z) \cdot C(z) \cdot S(z)-B(z) \cdot D(z) \cdot Q(z)+K_{P} \cdot A(z) \cdot D(z) \cdot S(z)=P(z)
$$

The desired polynomial $P(z)$ is formulated as:

$$
P(z)=z^{4}+p_{3} z^{3}+p_{2} z^{2}+p_{1} z+p_{0}
$$

The vector of control system parameters $\left[K_{P \dot{x}}, q_{1}, q_{0}, s_{0}\right]$ can be derived from Diophantine equation for determine two the same pairs of stable poles, which are obtained for assumed dumping coefficient $\xi$ and pulsation $\omega_{0}$ of closed-loop control system:

$$
z_{1,2}=\exp \left[\left(-\xi \omega_{0} \mp j \omega_{0} \sqrt{1-\xi^{2}}\right) T_{0}\right]
$$

where: $T_{0}$ - sample time. 
The parameters of control system are calculated from equations system (9) which was derived from Diophantine equation (6).

$$
\left[\begin{array}{ccc}
a_{1} & 1 & 0 \\
a_{0} & a_{1} & 1 \\
0 & a_{0} & a_{1} \\
0 & 0 & a_{0}
\end{array}\right]\left[\begin{array}{cc}
1 & 0 \\
c_{0} & 1 \\
0 & c_{0}
\end{array}\right]\left[\begin{array}{c}
1 \\
s_{0}
\end{array}\right]+d_{0}\left(K_{P \dot{x}}\left[\begin{array}{cc}
1 & 0 \\
a_{1} & 1 \\
a_{0} & a_{1} \\
0 & a_{0}
\end{array}\right]\left[\begin{array}{c}
1 \\
s_{0}
\end{array}\right]-\left[\begin{array}{cc}
0 & 0 \\
b_{1} & 0 \\
b_{0} & b_{1} \\
0 & b_{0}
\end{array}\right]\left[\begin{array}{c}
q_{1} \\
q_{0}
\end{array}\right]\right)=\left[\begin{array}{c}
p_{3} \\
p_{2} \\
p_{1} \\
p_{0}
\end{array}\right]
$$

\section{Fuzzy robust anti-sway crane control system}

The proposed method of determining the parameters of conventional discrete anti-sway crane control system, based on pole placement method (PPM), can be used to built robust crane controller. Robust control system can be based of gain-scheduling system with parameters of discrete controllers chosen basis of changes the key-scheduling variables, rope length $l$ and mass of the load $m_{2}$. It requires to carry out identification of control object for chosen values rope lengths and masses of the load $\mathbf{L}=\left[l_{1}, l_{2}, \ldots, l_{n}\right]$ and $\mathbf{M}_{2}=\left[m_{21}, m_{22}, \ldots, m_{2 m}\right]$ that leads to obtain a set of operating points:

$$
\mathbf{O}=\left[o\left\{l_{1}, m_{21}\right\}, o\left\{l_{1}, m_{22}\right\}, \ldots, o\left\{l_{1}, m_{2 m}\right\}, o\left\{l_{2}, m_{21}\right\}, \ldots, o\left\{l_{n}, m_{2 m}\right\}\right]^{T}
$$

The consecutive operating points $o\left\{l_{i}, m_{2 j}\right\}$ and $o\left\{l_{i+1}, m_{2(j+1)}\right\}$ should satisfy the condition:

$$
\mathbf{A} \cdot \mathbf{C} \cdot \mathbf{S}+\mathbf{D} \cdot \mathbf{A} \cdot \mathbf{S} \cdot \mathbf{K}_{\mathbf{P} \dot{\mathbf{x}}}-\mathbf{D} \cdot \mathbf{B} \cdot \mathbf{Q} \in \mathbf{P}_{i j,(i+1)(j+1)}
$$

where:

$\boldsymbol{A}, \boldsymbol{B}, \boldsymbol{C}, \boldsymbol{D}$ - the matrixes of control object parameters in equation (9) for $l$ and $m_{2}$ changes $\left\langle l_{i}, l_{i+1}\right\rangle$ and $\left\langle m_{j}, m_{2(j+1)}\right\rangle$,

$\mathbf{K}_{\mathbf{P} \dot{\mathbf{x}}}, \mathbf{S}, \mathbf{Q}$ - the vectors of control coefficients in equation (9), that were determine for $\left\{l_{i}, m_{2 j}\right\}$ values,

$\mathbf{P}_{i j,(i+1)(j+1)}$ - the interval vector of coefficients desired characteristic equation $P(z)$ 


$$
\mathbf{P}_{i j,(i+1)(j+1)}=\left[\begin{array}{c}
{\left[p_{3 i j}, p_{3(i+1)(j+1)}\right]} \\
{\left[p_{2 i j}, p_{2(i+1)(j+1)}\right]} \\
{\left[p_{1 i j}, p_{1(i+1)(j+1)}\right]} \\
{\left[p_{0 i j}, p_{0(i+1)(j+1)}\right]}
\end{array}\right]
$$

The vector of desired coefficients $\mathbf{P}$ specifying for operating point $o\left\{l_{i}, m_{2 j}\right\}$ is determined for range of accepted changes of variables $\left\langle l_{i}, l_{i+1}\right\rangle$ and $\left\langle m_{j}, m_{2(j+1)}\right\rangle$.

$$
P(z)=\left(\left(z-\left[z_{1 i j}, z_{1(i+1)(j+1)}\right]\right)\left(z-\left[z_{2 i j}, z_{2(i+1)(j+1)}\right]\right)\right)^{2}
$$

In practice the vector $\mathbf{P}_{i j,(i+1)(j+1)}$ can be derived based of expected control aims expressed as setting time $t_{r}$, tolerance of setting variables errors, overshot $\chi$ over setting variable. The vector $\mathbf{P}_{i j,(i+1)(j+1)}$ can be found for (14):

$$
\mathbf{P}_{i j,(i+1)(j+1)} \quad \forall \xi \in\left[1,-\frac{\ln \chi}{\sqrt{\pi^{2}+\ln ^{2} \chi}}\right]
$$

The robust fuzzy anti-sway crane control system was built using TakagaiSugeno-Kang (TSK) fuzzy inference system (see Figure 4). Fuzzy TSK controller was elaborated based of time-discrete crane speed control system (see Figure 3) with added proportional controller of crane position $R_{x}(z)=K_{P x}$. 


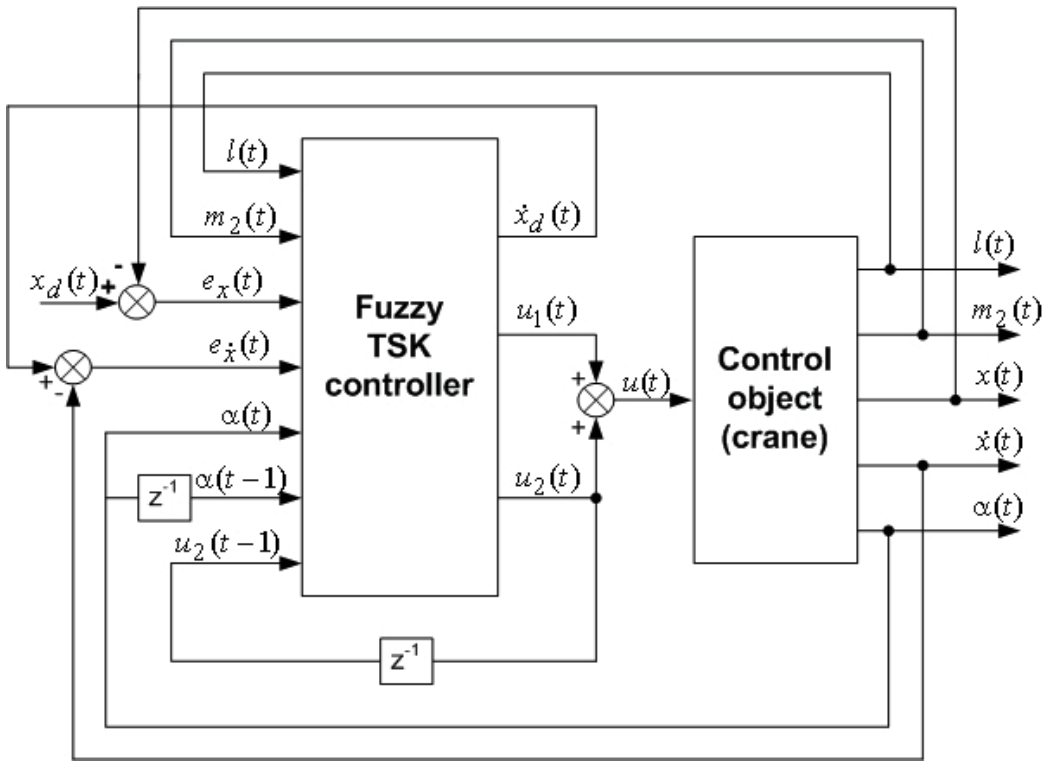

Figure 4. The robust anti-sway crane control system with the TSK fuzzy controller

The key-scheduling variables $l$ and $m_{2}$ are used in the fuzzification process of the TSK fuzzy system to derive membership coefficients $\mu(l)$ and $\mu\left(m_{2}\right)$ based of triangular membership functions $L M(l)$ and $L M\left(m_{2}\right)$ defined in antecedent of if-then fuzzy implications (see Figure 5). The fuzzy implications used in base of knowledge of the TSK controller have form:

IF $l$ is $L M_{i}(l)$ and $m_{2}$ is $L M_{j}\left(m_{2}\right)$

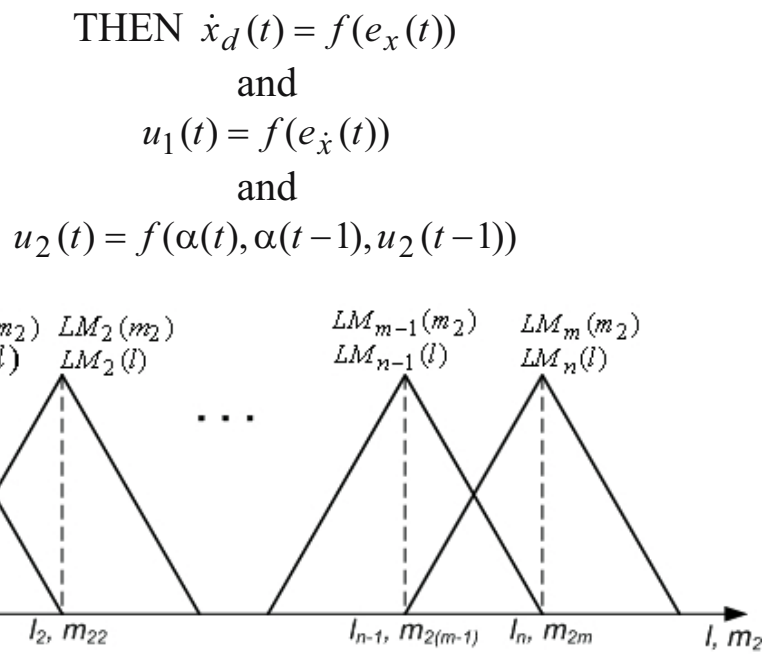

Figure 5. The membership functions used for scheduling variables $l$ and $m_{2}$ 
The outputs of the TSK controller $\dot{x}_{d}, u_{1}, u_{2}$ for each $k^{\text {th }}$ rule are calculated as a product of input and controller gains vectors $\mathbf{X}$ and $\mathbf{K}$ respectively.

$$
\begin{aligned}
& \dot{x}_{d k}(t)=\mathbf{X}^{T} \cdot \mathbf{K}_{x k}=\left[\begin{array}{c}
l(t) \\
m_{2}(t) \\
e_{x}(t) \\
e_{\dot{x}}(t) \\
\alpha(t) \\
\alpha(t-1) \\
u_{2}(t-1)
\end{array}\right]^{T} \cdot\left[\begin{array}{c}
0 \\
0 \\
K_{P x k} \\
0 \\
0 \\
0 \\
0
\end{array}\right] \\
& u_{1 k}(t)=\mathbf{X}^{T} \cdot \mathbf{K}_{\dot{x} k}=\left[\begin{array}{c}
l(t) \\
m_{2}(t) \\
e_{x}(t) \\
e_{\dot{x}}(t) \\
\alpha(t) \\
\alpha(t-1) \\
u_{2}(t-1)
\end{array}\right]^{T}\left[\begin{array}{c}
0 \\
0 \\
l(t) \\
0 \\
m_{2}(t) \\
e_{x}(t) \\
e_{\dot{x}}(t) \\
\alpha(t) \\
\alpha(t-1) \\
u_{2}(t-1)
\end{array}\right]^{T}\left[\begin{array}{c}
0 \\
0 \\
0 \\
0 \\
0 \\
0 \\
0 \\
q_{1 k} \\
q_{0 k} \\
-s_{0 k}
\end{array}\right]
\end{aligned}
$$

For $N$ rules the outputs of the TSK controller are calculated as follow:

$$
\dot{x}_{d}=\frac{\sum_{k=1}^{N} w_{k} \cdot \dot{x}_{d k}}{\sum_{k=1}^{N} w_{k}}, \quad u_{1}=\frac{\sum_{k=1}^{N} w_{k} \cdot u_{1 k}}{\sum_{k=1}^{N} w_{k}}, \quad u_{2}=\frac{\sum_{k=1}^{N} w_{k} \cdot u_{2 k}}{\sum_{k=1}^{N} w_{k}}
$$

where:

$w_{k} \quad$ - the weight of $k^{\text {th }}$ fuzzy rule,

$N \quad$ - the number of fuzzy rules defined in the TSK controller.

The vectors $\mathbf{K}_{x k}, \mathbf{K}_{\dot{x} k}, \mathbf{K}_{\alpha k}$ include gains of time-discrete control system (see Figure 3) that are derived for operating points $o_{k}\left\{l_{i}, m_{2 j}\right\}$ specified for key-scheduling variables ranges $l=\left\langle l_{\min }, l_{\max }\right\rangle$ and $m_{2}=\left\langle m_{2 \min }, m_{2 \max }\right\rangle$. The control signal is a sum of a speed control signal and a load swing control signal $u(t)=u_{1}(t)+u_{2}(t)$ calculated in each sample time. 


\section{Results of experiments carried out using laboratory model of an overhead travelling crane}

The experimental researches for robust fuzzy anti-sway control system were carried out using the laboratory overhead travelling crane with hoisting capacity $Q=150[\mathrm{~kg}]$. The software-hardware architecture of controlmeasurement system was based of the PC with control-measurement card and Matlab programming tools as well as the PLC (Programmable Logic Controller) which passes control-measurement signals between control object and PC (see Figure 6).

The parameters of the TSK controller were determine for operating points specified for key scheduling variables rope length $l=\{0,7 ; 1,2,1,7\}[\mathrm{m}]$ and mass of the load $m_{2}=\{10,30,50\}[\mathrm{kg}]$. The experiments were carried out for expected position of the crane (the bridge of the crane) $x_{d}=1[\mathrm{~m}]$ and chosen values of variables $l$ and $m_{2}$. The chosen results of experiments were presented in the form of time characteristics of crane position (see Figure 7 and 9) and the load swing (see Figure 8 and 10) (the load deviation $l \cdot \alpha$ from a vertical axe $O Y$ in assumed co-ordinate system $O X Y$ ).

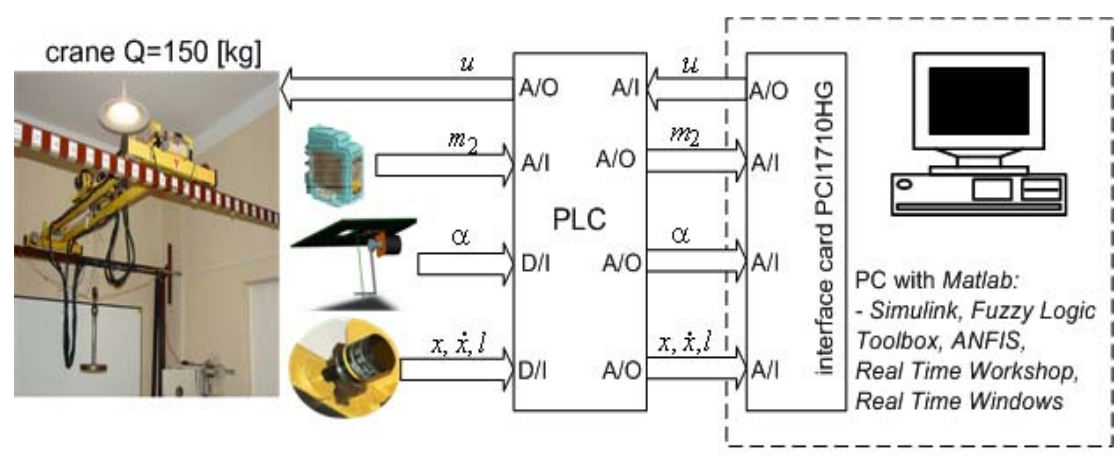

Figure 6. The software-hardware architecture of control system

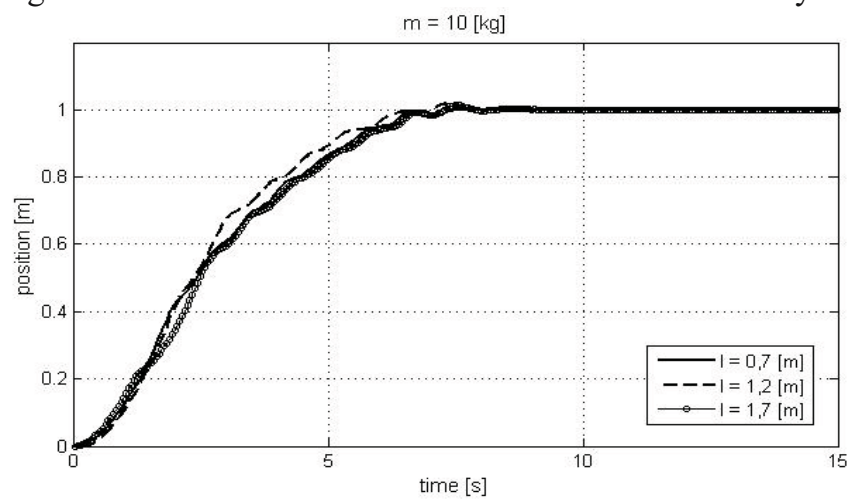

Figure 7. The crane position 


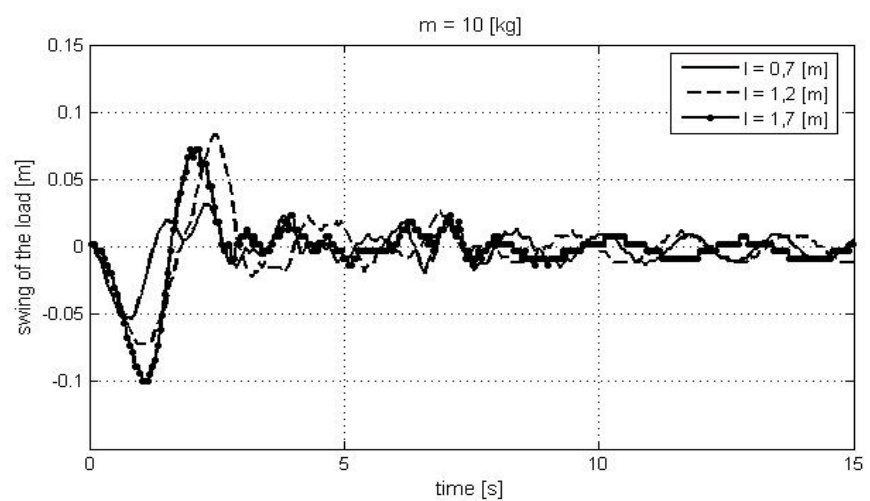

Figure 8 . The load swing $(l \cdot \alpha[\mathrm{m}])$

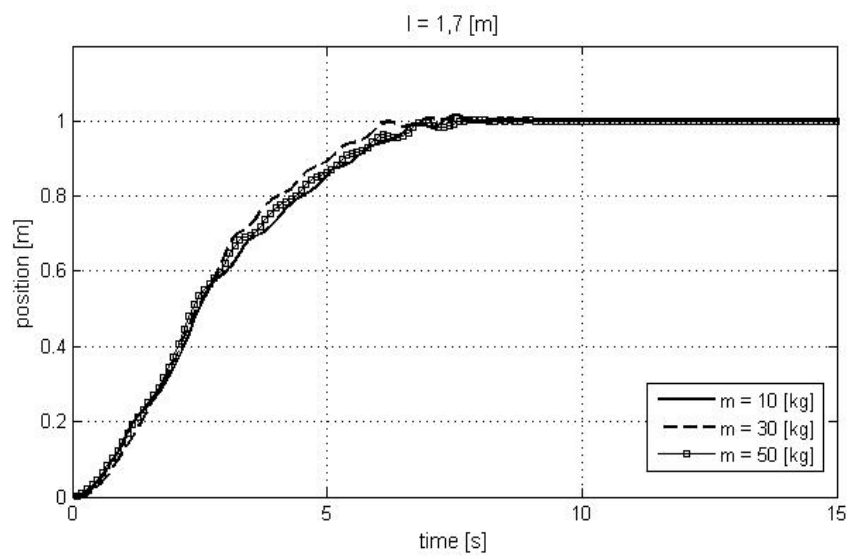

Figure 9. The crane position

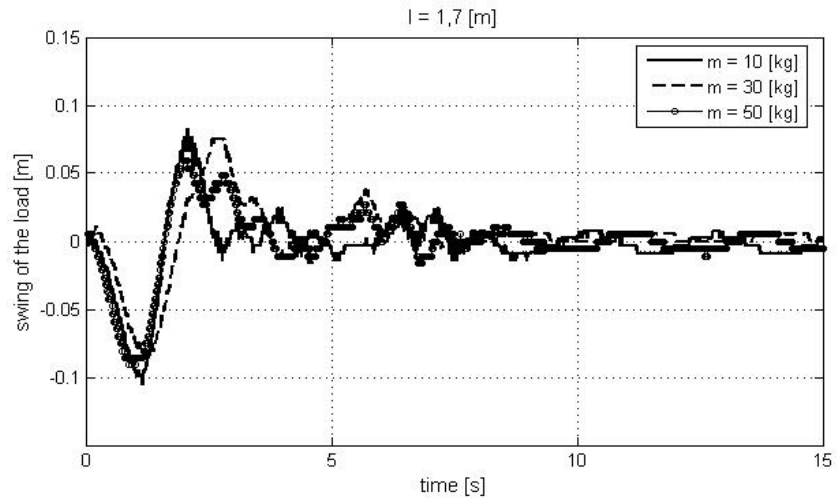

Figure 10. The load swing $(l \cdot \alpha[\mathrm{m}])$

The obtained results confirmed that the assumed aims for control system were achieved in satisfactory way. The control system with fuzzy controller TSK occurred robustness for taken into consideration ranges of scheduling 
variables changes $l=\langle 0,7,1,7\rangle[\mathrm{m}]$ and $m_{2}=\langle 10,50\rangle[\mathrm{kg}]$. The expected position of the crane and shifted load was achieved in time about 7 [s] with tolerance less then 0,02 [m]. The load swing is dumped at about 3-4 [s] after starting-up the driving mechanism of the crane and reduced under $0,015[\mathrm{~m}]$ after setting time 7 [s].

\section{Conclusions}

The paper presents methods of elaborating conventional anti-sway crane control system based of proportional-derivative (PD) controllers and pole placement method (PPM) as well as method of building the robust fuzzy crane control system. The methods of building gain-scheduling anti-sway crane control system was shown as well as solution of operating points selecting was explained. Based on presented solutions, the fuzzy robust crane controller with Takagi-Sugeno-Kang inference system was built. The fuzzy control algorithm was based of time-discrete crane control system with crane position and speed and the load swing controllers which gains were derived with using pole placement method for operating points chosen using formulated in the paper method.

The experiments with robust fuzzy anti-sway crane control system were carried out using the double-gird laboratory overhead travelling crane with hoisting capacity $Q=150[\mathrm{~kg}]$. The software and hardware architecture of the control-measurement system was presented. The results of experiments confirm robustness of proposed control system with the TSK fuzzy controller. The satisfactory results of carried out researches allow to state that proposed solutions and methods give possibility to improve the control quality of the crane control system as well as exploitation quality and reliability of material handling devices.

The research project is financed from the Polish Science budget for the year 2009.

\section{References}

1. Benhidjeb A., Gissinger G.L.: Fuzzy control of an overhead crane performance comparison with classic control. Control Engineering Practice, Vol. 3, No. 12, pp. 1687-1696, 1995.

2. Giua A., Seatzu C., Usai G.: Observer-controller design for cranes via Lyapunov equivalence. Automatica, V. 35, No 4, pp. 669-678, 1999.

3. Hicar M., Ritok J.: Robust crane control. Acta Polytechnica Hungarica, Vol. 3, No. 2, pp. 91-101, 2006. 
4. Lew J.Y., Halder B.: Experimental study of anti-swing crane control for a varying load. Proceedings of American Control Conference, V. 2, pp. 1434-1439, 2003.

5. Mahfouf, M., Kee C.H., Abbod M.F., Linkens D.A.: Fuzzy logic-based anti-sway control design for overhead cranes. Neural Computating and Applications, Vol. 9, pp. 38-43, 2000.

6. Mendez J.A., Acosta L., Moreno L., Torres S., Marichal G.N.: An application of a neural self controller to an overhead crane. Neural Computing and Applications, No 8, pp. 143-150, 1999.

7. Nalley M., Trabia M.: Control of overhead crane using a fuzzy logic controller. Journal of Intelligent and Fuzzy Systems, Vol.8, pp.1-18, 2000.

8. Smoczek J., Szpytko J.: Human-Machine Interface implementation in designing crane control based on fuzzy logic algorithm. Proceeding of the $17^{\text {th }}$ IFAC World Congress, Seoul, Korea, pp. 15100-15105, 2008.

9. Smoczek J., Szpytko J.: The neuro-fuzzy adaptive anti-sway crane control system. Proceeding of the $12^{\text {th }}$ IFAC Symposium on Control in Transportation Systems CTS'09, Redondo-Beach, USA, pp. 58-63, September 2009.

10. Yi J., Yubazaki N., Hirota K.: Anti-swing fuzzy control of overhead travelling crane. Proceedings of IEEE International Conference on Fuzzy Systems, pp.1298-1303, 2002.

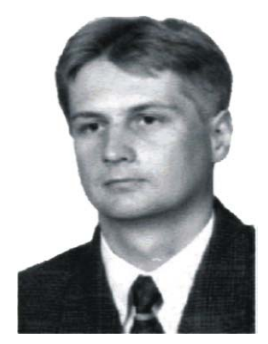

Dr inż. Jarosław SMOCZEK, AGH University of Science and Technology, Faculty of Mechanical Engineering and Robotics. Specialist in designing and exploitation of transport systems and devices, automatics, monitoring and diagnostics. Author or co-author of more then 40 publications, both in Polish and English.

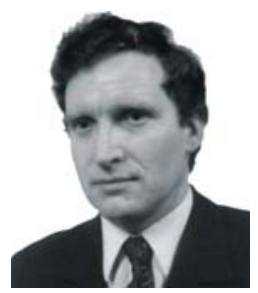

Prof. dr hab. Inż. Janusz SZPYTKO, AGH University of Science and Technology, Faculty of Mechanical Engineering and Robo-tics. Specialist in designing and exploitation of transport systems and devices, automatics, safety and reliability, monitoring and diagnostics, decision making systems, telematics. Author or co-author of more then 300 publications, both in Polish and English. Member of: STST KT PAN, TC IFAC, SEFI, ISPE, PTD, PTB, PSRA, ISA, SITPH and others. Visiting professor at the universities in: UK, France, Canada, Italy, Greece, Canada, Laos. Coordinator and member of several R\&D projects both national and international. Organizer and member of several scientific and programme committees of international and national conferences and symposiums 